\title{
Physical Cultures of Stigmatisation: Health Policy \& Social Class
}

\author{
by Emma Rich, Laura De Pian and Jessica Francombe-Webb \\ University of Bath; University of Bath; University of Bath
}

\author{
Sociological Research Online, 20 (2), 10 \\ $<$ http://www.socresonline.org.uk/20/2/10.html> \\ DOI: $10.5153 /$ sro.3613
}

Received: 15 Sep 2014 | Accepted: 11 Feb 2015 | Published: 31 May 2015

\begin{abstract}
In recent years, the increasing regulation of people's health and bodies has been exacerbated by a contemporary 'obesity discourse' centred on eating less, exercising more and losing weight. This paper contributes to the growing body of work critically examining this discourse and highlights the way physical activity and health policy directed at 'tackling' the obesity 'crisis' in the UK articulates numerous powerful discourses that operate to legitimise and privilege certain ways of knowing and usher forth certain desirable forms of embodiment. This has given greater impetus to further define the role of physical activity, sport and physical education as instruments for addressing public health agendas. It is argued that these policies have particular implications for social class through their constitution of (un)healthy and (in)active 'working class' bodies. One of the most powerful forms of stigmatisation and discrimination circulating within contemporary health emerges when the social and cultural tensions of social class intersect with obesity discourse and its accompanying imperatives related to physical activity and diet. This raises some important questions about the future of sport and physical activity as it is shaped by the politics of broader health agendas and our position within this terrain as 'critics'. Consequently, the latter part of the paper offers reflections on the nature and utility of our (and others') social science critique in the politics of obesity and articulates the need for crossing disciplinary and sectoral borders.
\end{abstract}

\section{Keywords: Health, Physical Activity, Policy, Social Class, Stigma, Physical Cultural} Studies

\section{Introduction}

There is no sure ground even for criticism (Latour 2004: 227)

1.1 Over the last ten years, along with other scholars, we have been exploring how a putative obesity epidemic has shaped the agendas of Physical Education (PE) and Physical Activity policies, practices and contexts. Partly, our sociological imaginations have focused on this because more than ever, 'risky' behaviours (excessive alcohol consumption, smoking, lack of physical activity, consuming foods high in saturated fat and sugar) that lead to 'risky' bodies (a risk to themselves and their life-expectancy, a risk to the financial viability of public health services) have emerged as a central concern for policy. As a result, health is constituted through regulative discourses, and over the last decade, this tendency has been heightened by a contemporary 'obesity discourse' (Evans et al. 2008). This has given greater impetus to further define the role of physical activity, sport and PE as instruments for addressing public health agendas to encourage people to exercise more in the 'battle against obesity'. Yet this is not without sociological critique and scholars have pointed out the potentially harmful effects of healthism as it has seeped into the very heart of the political agendas of sport and physical activity. A sustained body of conceptual and empirical critique has made clear the uncertainties and ambiguities within obesity science and the detrimental effects it can have for an individual's wellbeing (see Burrows and Wright 2007; Campos 2004; Campos et al. 2006; De Pian 2012; Evans et al. 2004; Evans et al. 2008; Gard and Wright 2005; Monaghan 2005; Rich et al. 2011; Warin et al. 2008). This work has also led to the development of sociological theories addressing the 'biopolitics' (Wright and Harwood 2009) of obesity and the 'body pedagogies' (Evans et al. 2008) through which we learn which bodies have value. 
powerful discourses that operate to legitimise and privilege certain ways of knowing and usher forth certain desirable forms of embodiment. Recent scholarship reveals how underlying poverty contributes to poor nutrition and weight gain rather than a neoliberal recourse focused on lack, or failure, of will by individuals (Warin 2014). Despite these insights, a circulating political rhetoric that disregards any significant consideration of the social determinants of health remains. Take for example our point of departure for this analysis: social class. Classlessness is enabled by both an 'abdication from acknowledging class relations' (Skeggs 2005: 54) and an omnipresent discourse of individualism that continues to dominate. We contend that one of the most powerful forms of stigmatisation and discrimination circulating within contemporary health emerges when the social and cultural tensions of social class intersect with obesity discourse. Specifically within the first half of this paper, we discuss the impact of policies' emphasis on behavioural models of health as this intersects with classed subjectivities; and we consider the ways that privileging these behaviour change models means that questions of social context remain under theorised and under explored empirically (Ong et al. 2014). We advocate alternative approaches predicated on the realisation of more nuanced understandings of health which consider the 'intersections' of health disparities and everyday meanings of the body (Van Amsterdam 2014).

1.3 Having offered this critique, we refocus our attention on the politics of that critique. In Bruno Latour's (2004) essay 'Why has critique run out of steam? From matters of fact to matters of concern'he questions the role of the critic arguing for a reappraisal of the nature of 'critique', suggesting that:

The critic is not the one who debunks, but the one who assembles. The critic is not the one who lifts the rugs from under the feet of the na?ve believers, but the one who offers the participants arenas in which to gather (247).

These are particularly pertinent concerns for this special issue focused on the political sociologies of sport and the various critical approaches to looking at political issues that emerge in sport. It is now over thirty years since Crawford (1980) coined the term 'healthism' to describe the constitution of good health as being a matter of individual prerogative; individual choice and simultaneously individual responsibility. This is a conceptualisation that has been readily extended and critiqued; Caroline Fusco (2006: 66), for example, expands healthism to introduce a notion of healthification in order to extrapolate 'the whole deployment of a field of discursive and material technologies and techniques, self and other administered that sustain the imperative' of healthy subjects, healthy lifestyles, healthy landscapes. What is more, there has been a groundswell of literature on school-health, PE, sport and physical activity that has variously made visible the increasingly individualised, moralised and performative approach to physical activity and its focus on health imperatives. Whilst the potentially harmful implications of these contexts have been made known, Walkerdine (2009: 200) reflects on the progress of that critique and asks 'how can critical intervention happen, what effectivity can it have'? Considering this very question and the state of play since the inception of more critical perspectives of health agendas within physical activity contexts, Wright (2014: 244) similarly asks 'whether it is possible to have a health education that enhances young people's health but is not individualizing, "othering", morally judgemental, motivated by political or economic ends...'

1.5 We echo the position of Bombak (2014) that policy makers need to engage more strongly with the applied work of social scientists in the design and development of public health policy and interventions. But how do we achieve this given that for thirty years such critique remains marginalised and silenced in dominant discourses of health? As Latour (2004: 247) articulates it, 'the practical problem we face, if we try to go that new route, is to associate the word criticism with a whole set of new positive metaphors, gestures, attitudes, knee-jerk reactions, habits of thought'. In questioning whether 'critique' has gone too far, Latour therefore raises some pertinent questions for our discussion about the future of sport and physical activity as it is shaped by the politics of broader health agendas and our position within this terrain as 'critics'. For us at least, Warin (2014: 3) seems to capture one of the central issues in the politics of obesity in that there seems to be 'a crucial impasse between fundamentally different and opposing understandings of obesity'. This is, of course, not limited to understanding 'obesity' and can no doubt be observed in the competing disciplinary logics and sensibilities that coalesce around different health and physical activity 'problematics'. Yet, whilst our sociological critiques have been important and offer counter perspectives to dominant obesity discourse, Mansfield and Rich (2013: 1-2) contend that '[t]here is a tendency in obesity debates to deconstruct dominant obesity discourse without offering some deliberations on how we might move the field forward'. In part then, scholars working in the contexts of physical activity and critical perspectives of obesity are confronted by some of the pertinent concerns raised by Latour regarding the nature and utility of our 'critique' although at the same time, the damaging socio-cultural impacts of the policies and practices associated with this discourse seem only to be gaining momentum.

1.6 Albeit modestly, in the final part of this paper we address some of these challenges, reflecting on the nature of the critique we offer and where these analyses might take us in terms of connecting with others across different disciplines and sectors. We stress the importance of border crossing (Giroux 1992; Mansfield and Rich 2013) in response to some of the concerns raised above about the politics of obesity and physical activity. In 
setting out a framework for the paper, we begin by locating our work within a Physical Cultural Studies (PCS) perspective, in part precisely because it advocates the need for finding points of connection across disciplinary boundaries.

\section{Physical Culture, Policy \& Power}

2.1 In this paper we endeavour to make visible some of the underlying assumptions about 'social class' that drive particular policy approaches to tackling obesity through physical activity and diet management and their subsequent prescriptions for health promotion and practice. This critique is underpinned by our collective grounding in physical cultural studies (PCS) and our praxis oriented moral agenda that is committed to border crossing and intervention. PCS is animated by its interdisciplinarity-'around the central thematic of physical activity' (Andrews 2008: 47) - and therefore it resists temptations to categorise or operationalise a rigid agenda. Instead PCS should be regarded as a sensibility or an approach that drives our enquiries and encourages us to draw on a range of theoretical and methodological perspectives in order to advance a fluid, radical contextualisation of the everyday physical (Silk and Andrews 2011). PCS draws attention to the ways that corporeal practices and subjectivities are organised, represented and experienced in relation to the operation of social power and the impact of this across health and physical cultural programmes and policies, the aim being to gain 'an understanding of the interrelationships among practices in exercise, health, nutrition, sport and physical leisure to promote individual and social betterment' (Ingham 1997: 166).

From this perspective we seek to bring to light the way that the human body and care of the (un)healthy, (in)active self is conceptualised and represented within policy - pointing towards the everyday lives a/effected by such governance. Therefore, ours endeavours to be an engaged, contextualised and politicised form of intellectual inquiry. The unique and perhaps most indispensable notion to take from this approach is the need to take seriously the axes of power that penetrate and are contested at particular moments in history. This contextual mapping of social formations is animated by subjectivity and power, 'how human subjects are formed ... how they experience cultural and social space' (Miller 2001: 1) and how they position themselves. For this paper, this commitment to exposing the power relations that shape public health policy involves a way of thinking about the play of correspondences, non-correspondences and contradictions that refrains from reductionism, determinism or essentialism and instead works with dialogic, relational, layered and disparate complexities in order to highlight the lived experiences of policy and the consequences for everyday life (Slack 1996). This analysis is at once a way of conceiving 'how ideological elements come, under certain conditions, to cohere together within a discourse, and a way of asking how they do or do not become articulated, at specific conjunctures' (Hall 2011: 141-142, our emphasis). As a result, contending with the dynamism and multiplicity of our epoch is no easy endeavour because it is shaped by intersecting articulations of body politics and health related discourses and practices. Our task is to locate these within an assemblage of social, political, economic and technological forces (Christians 2000; Denzin 2005).

2.3 The relationship between cultural studies and sociology in general and the contingent PCS[1] and sociology of sport projects specifically, is one that is complicated, manifold and longstanding and it is beyond the remit of this paper to delineate this in detail (see Andrews 2008; Turner 2003). Suffice to say, that our position is one that sees (physical) cultural studies and sociology as being at their best when they are in dialogue; when they cooperate, even merge (Turner 2003). Subsequently, we advocate the need for stronger engagement with sociological research to better address the complexities of socio-cultural inequities. These political sociologies of inequity, we contend, contribute significantly to debates around culture and the development of policy directed at health, weight and physical activity. Given our collective grounding in PCS, we see that a sociological perspective is invaluable-especially in relation to an intersectional exploration of policy, theories of subjectivity and the 'classed' subject as in a state of becoming (Coleman 2008).

2.4 In doing so, papers such as this one focus on the contexts that contribute to inequalities and possibilities for social change through physical (in)activity, embodied health and emotional wellbeing. In what follows below, through our PCS project, we endeavour to articulate policy in a more nuanced and interdisciplinary manner, and point towards the need to develop policy in relation to experiences, meaning, shaping of subjectivities and wellbeing.

\section{Behaviour Change Models of Health and Physical Activity Policy - Implications for Social Class}

3.1 In recent years the shifting responsibility for health from the state to citizen has emerged against a sociopolitical backdrop of rising neoliberalism, austerity and welfare cuts including the radical reform of the NHS in 2010 (see Timmins 2012). Through policies seeking to tackle the 'war on obesity' Monaghan 2008), information about food and physical activity continues to be tied to the 'risks' of being overweight and obese (e.g. diabetes 
and heart disease). Many UK health and physical activity policies are underpinned by this logic and therefore draw from models of behavioural change (Ong et al. 2014) that promote self-management and individualised choice. Attention of this kind has been increasingly directed at children and young people, a population defined as most 'at-risk' of being affected by the ever increasing 'obesity crisis'. This, coupled with the widespread belief that health-related behaviours and attitudes (namely relating to diet and physical activity) are formed during childhood (Food and Drink Federation 2004; Hark and Deen 2005; Jefferson 2006), has resulted in a variety of UK government early intervention strategies targeting schools, families and wider community settings, as the key to tackling obesity (Department of Health 2004; 2005; 2008). Take, for instance, the information gathering and health monitoring techniques that exist in UK schools, such as the National Child Measurement Programme and the introduction of biometric fingerprint scanning systems to record information about young people's lunchtime meal choices. Both of these monitoring techniques are designed to 'inform local planning and target local resources and interventions' (Department of Health 2006) and allow information to be fed back to parents via a report which can be used to assess the extent to which their child is/should be complying with 'expert' health knowledge. What is more, a plethora of government health policies and initiatives have been introduced in the UK over the last decade, through which individuals have become increasingly accountable for their own and others' health. Central to this health discourse is the idea that fatness is the result of an individual's lifestyle and therefore remains an issue of choice and responsibility. This neoliberal perspective dominates current public and scholarly debate about weight, (in)activity and health (Rich, Monaghan and Aphramor 210; Solovay and Rothblum 2009) with the effect that health is conceived as equally accessible and achievable by all following the correct type and amount of investment in the self. Health-related policy is subsequently premised on the notion that individuals are free to make correct lifestyle 'choices'; that individuals' agency around 'health' is unrestrained and free from structural inequalities (eg socio-economic), which may have significant bearing on which choices are available. This is surprising given that successive governments' documentation of varying obesity levels between socio-economic groups has clearly shown that obesity might more reasonably be regarded as a 'disease of poverty' (Smith 2004 in Fox and Smith 2011). Hence, embedded within government health and physical activity policy aimed at tackling the 'obesity epidemic' is an assumed relationship between an individual's knowledge about lifestyle choices and risks (largely concerning diet, exercise and an appropriate body weight) and their performance of government-prescribed health behaviours. This hierarchical approach is summarised here as: expert knowledge = 'correct' lifestyle choices = 'health' and has been illustrated by De Pian (2013) (Figure 1):

Figure 1. Knowledge-Deficit Model for Health Education (De Pian 2013)

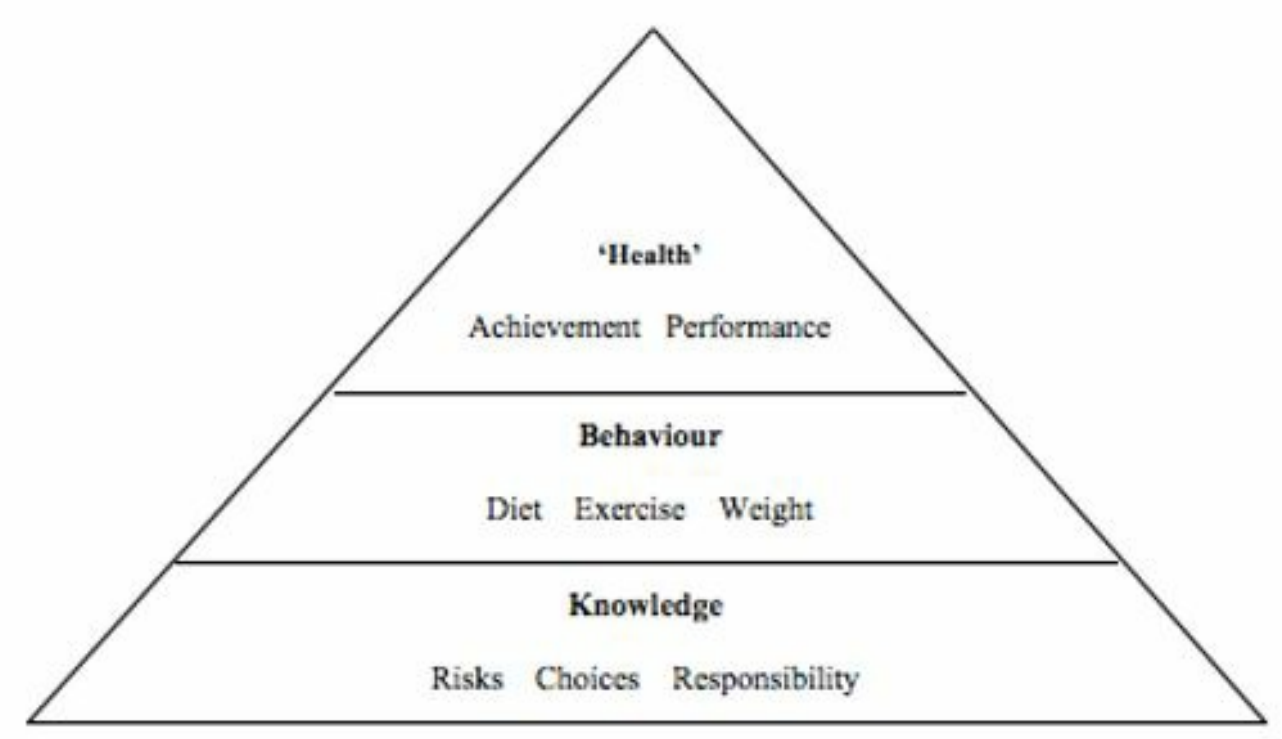

This behaviour change model, and the neoliberal principles underpinning it, frame 'health' as an entity to be achieved and continually performed by individuals. The 'obesity epidemic' is, therefore, largely attributed by government health officials (in the UK and elsewhere) to a 'knowledge deficit' among certain individuals and sections of the population. It can be argued that such models of behaviour change privilege certain (middle class) ways of 'knowing' and 'being' which marginalise and pathologise the working classes. Related policies, we argue, perform a range of value-laden functions through their principles of regulation and, furthermore, through their recontextualisation across a range of social contexts where the promotion of physical activity is tied to improved health evidenced through a slender body. To this extent, the language of health is politicised from the outset since it requires identifying particular individuals and lifestyles where such 'risk' is of concern and where 
health interventions are deemed to be necessary. Weight therefore serves as a marker of social status (Farrell 2011) and hence, this discourse contributes to the reproduction of extant social hierarchies and power structures whereby 'fatness' is a penalty of laziness, a criticism most often directed at the working classes. Rail and Lafrance (2009: 75) opine that the soft (Jeffords 1994), fleshy body is indicative of the 'unproductive body that has been and continues to be overly reliant on the welfare state'. The working classes are therefore pathologised as a 'risky' population who require government intervention in the form of education: to be enlightened about the lifestyle choices which lead to a slender, healthy body ideal. Given that obesity is especially prevalent 'among poor and minority groups who live in disadvantaged areas' (Puhl and Heuer 2010: 1021), this creates a stigmatising public discourse about social class and moral worth that is, as Graham (2012) suggests, more than ever centralised on the body and behaviour. This, of course, obscures the socio-determinants that 'underpin the political economy of health' (Cohn 2014: 160); marking those without the financial, social, embodied capital as 'other' and adding to their 'multiple stigmatized statuses' (Puhl and Heuer 2010: 1021).

This pathologizing of particular class-based subjectivities is replete across policy contexts. The decontextualisation and individualisation that has seeped into policy has meant that social determinants of health such as social class have become an 'unthought known' (Bollas 1987 cited in Walkerdine 2009). Vital to our analysis is our contention that class is not simply brought into fruition through objective empiricism alone, but is formulated upon a much broader, more fluid notion of differentiation (Skeggs 2004) that is grounded in people's identities, cultural and bodily practices, lack of knowledge and its 'enduring subjective existence as lived experience' (Munt 2000: 3). This is optimised in the UK government's recent policy on Reducing Obesity and Improving Diet (2013). This document outlines the spiral of 'problems' associated with being overweight, including risks to work opportunities and mental health. The cyclical effects of the consequences of eating too much and exercising too little-if we follow the policy line-can be avoided/overcome if individuals 'eat and drink more healthily', make healthier choices and 'be more active'. What is missing from this text is any consideration of the significant changes that 'have taken place in the food environment'; the increase in the accessibility of inexpensive, calorie dense foods and beverages 'in contrast to increasing prices of fresh fruits, vegetables, fish and dairy items' as well as urban planning that has reduced the number of spaces suitable for sport and physical recreation (Puhl and Heuer 2010: 1021). Nevertheless, rather than interfere with the logics of the free market, policies have deployed strategies of individual knowledge enhancement and motivation as key change agents. Notions of individual responsibilisation cut across political and popular idiom and as a result, health disparities such as inadequate nutrition, the availability of fresh food, substandard housing and decreased access to and use of, health care services, access to physical activity sites are silenced irrespective of the fact that they are central in the (re)constitution of good health. Likewise, any underlying and intersecting discourses of social class, race, ethnicity, disability as they pertain to healthy activity and food 'choices' are not legislated for.

In what can be read as a distinctively gendered, sexualised and classed approach to health provision, the Start4Life Programme (Department of Health 2014) serves as another example of such behaviour change intervention which recasts parents as responsible for the weight of their child/ren (Zivkovic et al. 2010). The virtues of middle classness are palpable within this policy that, among other things, gives dietary advice for expectant parents. An assumed knowledge gap is exposed in the programme's guidance for friends, family and parents-to-be to share information via text and email. Although not steeped in directives explicitly aimed at the working classes we recognise, as Bottero (2004) does, that class does not have to be explicitly verbalised and depicted for class-based processes, judgements and assumptions to be made. Research reveals that inadequate motherhood is one such assumed 'vector of deficiency' from which working class females are abjectified (Tyler and Bennett 2010: 385, see also Lawler 2004). This policy then speaks to the cultural imperative to vilify working class females as inadequate mothers likely to threaten the health and weight of their unborn child through their own poor consumptive choices during pregnancy as well as demonstrates the way that health related to diet and exercise is interpolated into a gamut of policy contexts addressing a range of other social goals.

In this vein, The Troubled Families programme, launched by the UK government in 2011 is a government/local authority strategy of 'intensive intervention' for families 'at risk'. 'Troubled Families' are defined as 'those that have problems and cause problems to the community around them, putting high costs on the public sector' (Department for Communities and Local Government 2014). Whilst The Troubled Families programme is ostensibly a holistic intervention for families living in poverty, in receipt of benefits and presenting problems related to crime, anti-social behaviour, education attendance, living conditions and health, the 'Working with Troubled Families' guide to the evidence and good practice (2012) utilises the consumptive practices of one of the families as indicative of the 'chaotic circumstances' they are living in. Food preparation, or lack thereof, becomes a signifier of dysfunction. Drawing on research conducted by Boddy et al. (2012) the guide provides examples of the consumptive chaos and the recommended best practice response and we see that diet is now constitutive of deprivation and disorder: 
'I [family worker] took her food shopping so that she could better understand what she was feeding her children wasn't appropriate ... She didn't know how to cook so for her it was easier to send the children out to play with a couple of chocolate bars than actually sit them down and do structured things together' (Working with Troubled Families 2012: 21-22)

What is more, the tenets or categories of this policy document have been recontextualised multifariously for local discretion and interestingly, in light of the topic of this special issue, physical activity and community sport are prevalent forms of advocated family intervention. Tackling 'Troubled' Families in Tower Hamlets (2014: 4 ) is one such example whereby making changes at home 'which make it easier ... to eat healthier food, enjoy a more active lifestyle' are seen as being at the crux of healthy families that are not burdened by lack of 'selfconfidence and poor emotional and mental wellbeing'. The scheme is aimed at empowering 'longer-term behavioural changes amongst families' and comments anecdotally that parents have begun 'cooking fresh food and walking the children to school' (Tackling 'Troubled' Families in Tower Hamlets 2014: 4). Moreover, parent ambassadors within the area have begun to organise and promote exercise classes to parents and the wider community. In this sense, policy texts are encountered as relational and heavily invested with judgements and assumptions about the 'correct' conduct of the body. Lawler (1999: 5) suggests:

One way in which class inequality works is through making working-class subjectivities pathological, so that class relations are not just economic relations but also relations of superiority/inferiority, normality/abnormality, judgement/shame.

3.7 This class-based discrimination on the basis of a lack of knowledge and skills often comes at the expense of contextualisation (Bernstein 1990). And, as we have argued elsewhere with colleagues Fvans et al. 2011), here we find it useful to think of such policy through Bernstein's (990: 102) conceptualization of 'text' and its specific relations of power. Bernstein argues that a text can be 'privileged in the sense that specific meanings within context have priority' and such meanings 'confer differential power upon speakers'. He argued that the 'basic question to be asked when considering issues of cultural reproduction is always with reference to the privileging pedagogic text' (172). This has utility in understanding the relationship between policy and the powerful processes of stigmatising weight and inactivity. It does so by drawing attention to how the individual is placed in 'relation to this text in terms of his/her social class, gender, race attributes, or any other discriminating attributes' (176). These policies and privileging texts are situated in an assemblage within which there is a 'particular logic of care' (Mol 2008) one that is focused on increased responsibility, control and choice. From this perspective, this privileged text therefore converges upon different bodies and subjects in different ways, favouring some and rendering others as abject.

Such policies have emerged at a time when weight-related stigma is positioned as a mostly acceptable prejudice in contemporary western society (Bombak 2014; Burdard 2009; Carels 2014; Rothblum and Solovay 2009), particularly those social contexts where body size constitutes one of the dominant criteria through which bodies are read and judged (Van Amsterdam 2013; Evans et al. 2008). The implications of this relationality of power-knowledge have long been established-where health conditions are understood as the result of individual responsibility there tends to be high levels of associated stigma attached to that condition (Weiner et al. 1988). These a/effects appear irrelevant though as Bombak (2014:3) argues, 'this work is generated from within a biomedical institution, it is presumed to be unquestionably objective... disqualifies concerns of how this research may affect or be affected by anti-fat bias'. From a PCS perspective, these are questions not only related to the physiology and etiology of health, they are also explicitly social, political and ethical questions since in their wake, the subsequent distribution of resources is framed through identifying 'causal' factors which can be reduced to the choices made by an individual. Individuals become positioned both as a subject that is 'at risk' and to be managed but also as a subject (the individual) to be held accountable. Diet, exercise and weight loss are therefore mobilised as moral practices of the (un)disciplined 'self' articulated through these policies. The political implications of this are becoming apparent. For example, in arguments about health-care priorities and rationalising attempts to 'cure' an overburdened NHS, discussions framed around who is deserving of resources are gaining momentum. Such policies could have a dramatic impact on the stigmatization of certain populations who find themselves subject to questions about the role of healthcare in the treatment of conditions when it is perceived, naively and deterministically, to be simply brought about by lifestyle choices. In 2013, a report by think-tank Demos - sponsored by a private health insurance company-made the headlines in the UK after it advised that 'people who lead healthy lifestyles should be rewarded with easier access to healthcare' and explores the impact of having a more 'responsible' population (NHS 2013). Governments are also turning to digital healthcare systems in an attempt to enhance such individual responsibility (Rich 2014). In the UK, the NHS has launched the 'Health Apps Library' to help individuals 'manage their health' (e.g. exercise apps) and in 2012 the UK Department of Health suggested that GPs should start prescribing health apps to their patients. 
epidemiology and medical sociology and the sociology of health and illness literature (Marmot and Wilkinson 2001; Peacock et al. 2013; Scambler 2012) that social inequality has deleterious consequences for population health. Indeed in the UK, the Whitehall studies identified the social gradient in health, where there exists a relationship between social hierarchy and mortality (Cabinet Office 2004). The implications of this for health and health-resources are clear; as Frohlich and Abel (2014) observe, those who are most deprived are the least likely to alter their health-related practices. Furthermore, Baum and Fisher (2014) argue that despite increasing evidence highlighting the importance of the social determinants of health, governments continue to draw from behavioural explanations in the development of policy. Consequently, there is a pressing need for a greater engagement with the social sciences in the design and development of health-related policies and interventions (see also Bombak 2014). In the discussion below, we reflect on possible avenues for that engagement.

\section{Discussion}

\section{Implications of a PCS approach}

4.1 Our argument in this paper aligns with the perspective of Cohn (2014) in that interventions formed from the basis of a health behaviour model may be limiting, not least because what might be identified as a priority focus within policy and intervention might not align with an individual's everyday practices, values or priorities. There is a need to attend more to the complexities of values in physical culture which move beyond a focus only on individual knowledge and choice. At present, '[t]he social, affective, material and interrelational features of human activity are effectively eliminated, as behaviour becomes viewed as an outcome of the individual and determined only by such things as motives, intentions and the subjective reception of norms and cues' (Cohn 2014: 159). The multiple meanings that people attach to their moving bodies (embodied knowledges) as well as the diversity of ways and contexts through which this occurs also means understanding the influence of the intersections of axes of everyday life. Drawing from the work of Van Amsterdam (2013: 157), this means being attuned to the nuances of the 'intersections of body size with other axes of signification such as gender, social class, race/ethnicity, sexuality, dis/ability and age'. Cohn (2014) frames this as a move away from 'behaviours' which conceive health behaviour as 'discrete, stable, homogeneous and measurable' and towards a focus instead on practices. Reconceptualising health in terms of practices thus moves us closer to an understanding of the complexities of emerging and contingent aspects of health. This aligns with a PCS approach as it considers a broader range of activities values and relationalities that come to frame health practices. These sociological perspectives matter greatly in contemporary landscapes, given that, according to Baum and Fisher (2014) governments continue to be attracted to behavioural health promotion models despite their failure to reduce health inequities. With this in mind, perhaps now is a more apt time than ever to talk of class subjectivities as opposed to a unified classed position, and to consider how these are inflected, reiterated and produced through health policy and practices that reduce health to casual, individual 'behaviours'.

Often this messiness and the problematics of class boundaries are not accounted for in politicised-read popularised-articulations of population health and wellbeing because, as Lawler (2005a; 2005b) argues, the respectable, law abiding, forward looking and hardworking (Vincent et al. 2010a, b) have been absorbed into the middle classes, consigning the 'rough,' the contagion, to the 'outside.' Often, therefore, it is precisely the overarching and problematic, monolithic signifiers of the working class (Skeggs 2004; Vincent et al. 2010a, b) recognisable by their 'social exclusion' and their disordered, 'soft' bodies - that are deployed, called upon, judged and rationalised within policy in the interest of easier and more efficient governance. We, with others (Skeggs 2005; Walkerdine 1990), read these signifiers in distinctively classed terms and contend that references made to inadequate amounts of time spent exercising, the consumption of calorific food and drink (Reducing Obesity and Improving Diet 2013), lack of knowledge-sharing and learning the body whilst pregnant (Start4Life) and having a kitchen lacking in functioning utilities such as a cooker and fridge-freezer (Troubled Families) are conceived as representations of the disaffected element of the working class populous (the work-shy, lazy, fast food consuming) who are exposed by their passivity and their apparent acceptance of welfare provision. Within this political, social and historical milieu, fatness has become equated with impoverished subjectivities that are wrought with contempt over an assumed lack of personal investment in health and wellbeing. We appreciate that this as a particularly contextualised-and potentially oxymoronic-form of class embodiment that is a departure from past understandings of the working class (male) body as an instrument of labour and a demonstration of physical investment in work: evidenced through a healthy and strong body. This shifting struggle over the legitimate body and the legitimate use of the body (Bourdieu 1991) makes visible the historically contingent and partial picture of class segregation and subordination [2] that fails to engage with the nuances and intricacies of class as a lived experience; the stories of social class and the discourses that are articulated in, on and around classed corporealities that 'encircle men, women and children on a daily basis' (Weis 2004: 4). 
There is clearly a need to challenge these health disparities but in this final part of the paper, and connecting with the themes of the special issue, we need ask what is sociology's political utility in the landscape of heated contemporary politics of obesity? Here, we agree with Gard (2011) that the task for both sceptics and protagonists of the obesity debate is to explore the complexities of health Elsewhere, Monaghan (2013: 84) suggests that 'naïve realism is untenable and debating obesity should not be reduced to a crude case of angels versus devils (the honest versus the dishonest, or the competent versus incompetent).

The intention of our critique then is not simply to replace one knowledge form with another. Of course, our narrative began in this paper by contributing to a sociology of knowledge and the pedagogical and policy transactions that knowledge informs. But, we suspect, along with a good many others, that sometimes there are similar interests, common grounds with those we least expect (Gard 2011). This requires an openness and willingness to engage in debate about how different professions and interest groups can advance health policy and practice. Whilst we are not suggesting that socio-cultural perspectives ought to replace other knowledge forms in the constitution of addressing health problems, we see a space for counter perspectives and critical voices offering alternative health paradigms that are systematically marginalised or silenced in this discourse. So how do we better 'find arenas in which to gather'(Latour 2004: 247). As 'critics' presenting our work at related conferences and events, we have even been asked 'don't you care about the health of children? Don't you want them to be physically active? healthy?' Latour (2004) asks 'can we devise another powerful descriptive tool that deals this time with matters of concern and whose import then will no longer be to debunk but to protect and to care, as Donna Haraway would put it?'. Foremost in our position is a concern with precisely the need to protect and care, to advance understandings of health that progress the health and wellbeing of individuals, particularly those that are most marginalised and face health disparities. It seems, therefore, that something is lost in translation.

In considering the future direction of how we might begin to address this, Mansfield and Rich (2013) have begun to draw from Giroux (1992) in exploring how border crossing within assemblages of health, might lead to new perspectives/understandings of physical activity and health. Giroux (1992) articulates this need for border crossing as moving across 'artificial' institutional barriers. Building on this work and perhaps aspirational in our ideals, we appeal for progress through different types of border crossing, including but not limited to ideas, communities, professions and disciplines to find spaces for ethical and respectable dialogue.

\section{Crossing intellectual/disciplinary boundaries in Health research}

4.6 These are concerns not only for those addressing 'obesity'; they also speak to broader relationships between sociologists of sport/health and 'other' (bio/health) sciences where the focus is of a shared concern (e.g. health and enhancing physical activity). We need to ask what forms of knowledge we exclude, whose voices we make available in this process of forming privileging texts; a task for us all, regardless of disciplinary or intellectual orientation. In doing so, we might move beyond tendencies towards theoretical fundamentalism and better understand and address areas of shared substantive interest and concern. For Giroux (1992: 29) this partly involves a process of unlearning one's privilege so as to engage with 'different cultural codes, experiences and languages' and to learn the 'the limits of such codes, including the ones they use to construct their own narratives and histories'. Within PCS, we draw from an array of theoretical and methodological perspectives that often stem from, but are not limited to, work in sociology-namely sociology of sport and the body-psychology, media and communication studies, history, education, politics, geography and these are deployed in order to understand the social and embodied axes of gender, class, race, sexuality, disability differentiation (Wolff 1997). In each of our disciplines (physical cultural studies, sociology of PE, sociology of sport) we are deeply grounded in particular theoretical languages (e.g. post-structuralism, critical social theory) and their underlying codes. To 'unlearn' this, or at least problematise how we evaluate and produce knowledge, is no easy task and can leave us vulnerable to further marginalisation. Of course, when our own perspectives are repeatedly marginalised and abjectified, as has been the case at many conferences and events focused on 'obesity', such disciplinary boundaries/defences are quick to materialise.

4.7 Unlearning this privilege means crossing borders, including ontological and epistemological ones if we are to reach a 'shared understanding' (Monaghan 2013: 100). The weakening of boundaries, we hope, may help us to address the 'impasse' Warin (2014: 2) identifies, which 'sits on an ontological and epistemological divide between the materiality of obese bodies (biology) and the discursive construction of morally flawed bodies (social construction)' (Warin 2014: 3). No sociological theory alone can account for the complexities and potency of effects of culture (mattering of bodies) and the force of the body as a presence. As Warin (2014) and Evans, Davies and Rich (2013) make clear, this means acknowledging the limitations of a focus only on the discursive elements of obesity and certainly our own work can be found wanting in respect of this. In this vein, border crossing revisits some of the age old debates about nature/nurture, or as we have written elsewhere, between matter and mattering of the body (Evans, Davies and Rich 2013: 653). Like Peacock et al. (2013: 395) we see 
that these understandings can be 'strengthened by greater dialogue across epidemiology and the sociology of health and illness'. Whilst our work is still developing in this regard, others are making inroads to this form of engagement. In an excellent example of border crossing, Warin (2014: 5) illustrates how material feminism provides tools for 'rethinking how critical social scientists might approach obesity science' and opens up news pathways at 'practical, ethical and policy levels'.[3]

\section{Crossing sector boundaries}

Healthism is deeply entrenched, not only in policy contexts but within a range of advocacy coalitions that come to steer the role of physical activity and health. The potential for approaches which move beyond individualising frameworks seems limited. We might ask whose voices are actually heard in the processes informing policies? There is increasing recognition that such approaches fail to engage with those from marginalised groups (Ong et al. 2014), nor is sufficient attention paid to the interpretive agencies of individuals throughout this process, to consider the knowledge and experiences individuals bring to their encounters with policy and how this might shape their understandings of health and the relationships they develop with their bodies.

4.9 In their article exploring public health pedagogy, border crossing and physical activity at every size, Mansfield and Rich (2013) outline how cross sector spaces may have an important role in revealing the underpinning neoliberal interests of contemporary UK physical activity policy and practice and the above issues of voice. The potential for effective border crossing is indicative of Giroux's (2004: 13) appeal for 'creating a new language that extends the meaning of pedagogy as a form of cultural production that takes place in a variety of sites and is produced by a diverse number of cultural workers'. This means engaging much more strongly with communities, cultural workers, health communities, health volunteers in developing our knowledge of health practices. Indeed, a growing body of research has recently argued that if we are to fully and more accurately understand policy (what it is and how it functions), then it must be regarded as 'a process' (Ball et al. 2012; Evans et al. 2008), taking account of the various ways in which policy both shapes and is shaped by a multitude of situational and contextual factors as it is enacted in specific settings. Global, national and regional policies thus become localised as their enactments are enabled and/or constrained by context-specific factors. Hence,

[policy] texts cannot simply be implemented! They have to be translated from text to action - put 'into' practice - in relation to history and to context with the resources available. (Ball et al. 2012: 3).

4.10 The rapid growth of neoliberalism has impacted and reshaped the economic, political and social landscape, particularly for working class populations who have seen a decline in collective organisations and viable opportunities for expression. Peacock et al. (2013), drawing from Lamont (2009), proffer that this decline has ultimately resulted in more limited opportunities for class-based collective imaginaries to be mobilised in order to protect against symbolic violence. We suggest that this symbolic violence is notable across policy contexts, and restricted opportunities for collective action coupled with discourses of individualism mean that 'everyday explanations for inequalities have shifted ... with the space for shame becoming wider' (Peacock et al. 2013: 398). Shildrick et al. (2010) highlight the stigma and shame associated with the words poverty and poor let alone the way the body and the practices of the bodies - what it eats, drinks and how it moves - are deployed as rhetorics of signification/differentiation. Giroux (1992: 27) argues that those involved in public education and cultural work must engage in 'the unlearning of one's own privilege' in ways that enable the voices of others in cultural spheres to be listened. In this regard, a 'powerful role may exist for applied social scientists, such as anthropologists or sociologists, in exploring the lived and embodied experiences of this largely discredited population' (Bombak 2014: 1).

\section{Conclusion}

5.1 In this paper, we have brought to the fore the potency and effect of policy and in doing so contribute to understandings of health inequalities. In making clear the contemporary marginalisation of different bodies and subjectivities throughout health policy, we have attempted to shed light on the way that the operation of powerful health discourses are used to 'reinforce arguments of normalcy against the ruptures of social and cultural tensions' (Skeggs and Wood 2004: 559). In this process, physical activity is being further constituted across a range of policy texts as an instrument for addressing public health agendas. In doing so, we have attempted to make clear how neoliberal models of health behaviour come to represent particular moral ideals through which responsibility converges differently according to class (and other subjectivities). But more than this, in doing so, current policy and accompanying 'evidence' may fail to adequately account for particular health practices. In complex political economies of health and physical activity, we argue a more critical and complex insight is needed if public health is to more adequately address contemporary class based inequalities of health and move beyond individualising notions of physical activity. The identification of determinants or 'behaviours' cannot fully capture the contingent and multiple factors that come to shape health or inform opportunities for change. Culture, 
power, politics, material factors form part of complex assemblage that must be engaged with in attempts to bring about changes in physical activity. Albeit modest, this paper goes some way towards articulating the potential of sociological (and in particular PCS) approaches to 'counter the individualised notion of health behaviour' (Cohn $2014 ; 160)$. We have also attempted to unpack the consequences of this political economy of health. As our critique highlights, the ideological, economic and societal consequences of neoliberalism shape the constitution of UK policy that incorporates health, diet and physical activity as well as contemporary experiences of stigmatisation and individual shame (Peacock et al. 2013). The underlying values associated with responsibility, individualised choice and self-management come to position some communities/populations more favourably than others. Further work is needed to examine the implications of this in terms of the distribution of health resources in relation to particular communities and opportunities for physical activity.

\section{Notes}

Physical cultural studies (PCS) is significantly informed by the cultural studies project that emerged from the Birmingham School's Centre for Contemporary Cultural Studies (CCCS) in the 1960s. PCS 'consciously incorporates' CCCS' characterisation of cultural studies 'as a critical sensibility and approach toward interpreting culture's role in the construction and [lived] experience of' power and reinvigorates it through its 'concern with excavating how active bodies ... can only be understood by the way in which they are articulated into a particular set of complex social, economic, political, and technological relationships that comprise the social context' (Andrews 2008: 56).

A picture that fails to engage with the nexus of post-fordist and -industrial structural currents that have changed the cultural and occupational landscape through a growth of e-commerce, the expansion of conspicuous consumption and a decline in more 'traditional' working class jobs aligned to localised manufacturing and the reduction of trades unions (Giroux 2003; Peacock et al. 2013).

Warin argues that the 'the value of critique in a new materialist approach to obesity is that it can retain both elements of material/discursive without privileging either (Alaimo and Heckman 2008: 6)' Warin (2014: 18).

\section{References}

ALAIMO, S. and HEKMAN, S. (2008) Material Feminisms. Bloomington, IN: Indiana University Press.

ANDREWS, D. (2002) 'Coming to terms with cultural studies', Sport \& Social Issues, Vol. 26, No.1, p. 110-117.

ANDREWS, D. (2008) 'Kinesiology's inconvenient truth and the physical cultural studies imperative',Quest, Vol. 60 , No. 1, p. 45-62.

BALL, S, MAGUIRE, M. and BRAUN, A. (2012)How schools do policy: Policy enactments in secondary schools. London and New York: Routledge.

BAUM, F. and FISHER, I. (2014) 'Why behavioural health promotion endures despite its failure to reduce health inequities', Sociology of Health and IIIness, Vol. 36, No. 2 p. 213-225.

BERNSTEIN, B. (1990) Class, codes and control. Volume IV: The structuring of pedagogic discourse.London: Routledge.

BODDY, J, STATHAM, J, WARWICK, I, HOLLINGWORTH, K. and SPENCER, G. (2012) Health-related Work in Family Intervention Projects' Thomas Corum Research Unit, Institute of Education, University of London: London [online]: http://www.cwrc.ac.uk/documents/Final_FIPs_report(acceptedApril2012).pdf.

BOMBAK, A. (2014) 'The Contribution of Applied Social Sciences to Obesity Stigma-Related Public Health Approaches', Journal of Obesity Vol 2014 [online]: http://dx.doi.org/10.1155/2014/267286

BOTTERO, W. (2004) 'Class identities and the identity of class'. Sociology, Vol. 38, No. 5, p. 985-1003.

BOURDIEU, P. (1991) Sport and social class in Mukerji C and Schudseon M (Eds.)Rethinking Popular Culture: Contemporary Perspectives in Cultural Studies. London: University of California Press, Ltd, p. 357-373. 
BURGARD, D. (2009) What is Health at Every Size? in Rothblum E and Solvay S (Eds.)The Fat Studies Reader, New York: NYU Press, p. 41-53

BURROWS, L. and WRIGHT, J. (2007) 'Prescribing practices: Shaping healthy children in schools',International Journal of Children's Rights, Vol. 15, No. 1, p. 83-98

CABINET OFFICE. (2004) Work, Stress, Health: The Whitehall II Study. London: Cabinet Office.

CAMPOS, P. (2004) The Obesity Myth. New York: Gotham Books.

CAMPOS, P, SAGUY, A, ERNSBERGER, P, OLIVER, E. and GAESSER, G. (2006) 'The epidemiology of overweight and obesity: public health crisis or moral panic? Point-counterpoint', International Journal of Epidemiology, Vol. 35, No. 1, p.55-60.

CARELS, R. (2014) Weight Stigma: A Socially Acceptable Prejudice Paper presented at 2nd International Weight Stigma Conference. June 24th 2014, Canterbury, UK.

CHRISTIANS, C. (2000). Ethics and politics in qualitative research inDenzin N and Lincoln Y (Eds.) Handbook of Qualitative Research (2nd ed.), London: Sage Publications Ltd, p. 133-155.

COHN, S. (2014) 'From health behaviours to health practices: An introduction', Sociology of Health \& IIIness, Vol. 36, No. 2, p. 157-162.

CRAWFORD, R. (1980) 'Healthism and the Medicalization of everyday life', International Journal of Health Services, Vol. 10, No. 3, p. 365-388.

DENZIN, N. (2005). Emancipatory discourses and the ethics and politics of interpretation inDenzin N and Lincoln Y (Eds.) Handbook of Qualitative Research (2nd ed.), London: Sage Publications Ltd, p. 933-958.

DE PIAN, L. (2012) Emboldened bodies: social class, school health policy and obesity discourse. Discourse: Studies in the cultural politics of education, Vol. 33, No. 5, p. 655-672.

DE PIAN, L. (2013) 'Embodying policy? Young people, education and obesity discourse'(Unpublished Doctoral Thesis). Loughborough University, UK.

DEPARTMENT OF HEALTH. (2004) Choosing Health: Making Healthy Choices Easier. London: Department of Health Publications.

DEPARTMENT OF HEALTH. (2005) National Healthy School Status: A Guide for Schools. London: Department of Health Publications.

DEPARTMENT OF HEALTH. (2006) Measuring Childhood Obesity: Guidance to Primary Care Trusts[online]: http://www.dh.gov.uk/Home/fs/en.

DEPARTMENT OF HEALTH. (2007) Foresight - Tackling Obesities - Future Choices Project[Online]: http://webarchive.nationalarchives.gov.uk/+/www.dh.gov.uk/en/Publichealth/Healthimprovement/Obesity/DH_079713.

DEPARTMENT OF HEALTH. (2008) Healthy Weight, Healthy Lives: A Cross-Government Strategy for England Her Majesty's Government, England. London: COI.

DEPARTMENT OF HEALTH (2012) BMI Healthy Weight Calculator[online]: http://www.nhs.uk/tools/pages/ healthyweightcalculator.aspx?WT.mc_id=101007.

DEPARTMENT OF HEALTH. (2013) Reducing Obesity and Improving Diet [online]: https://www.gov.uk/government/policies/reducing-obesity-and-improving-diet.

DEPARTMENT OF HEALTH. (2014) Start For Life[online]: http://www.nhs.uk/start4life/Pages/healthypregnancy-baby-advice.aspx.

DEPARTMENT FOR COMMUNITIES AND LOCAL GOVERNMENT(2012) Working with Troubled Families. A Guide to the Evidence and Best Practice [online]: https://www.gov.uk/government/uploads/system/uploads/attachment_data/file/ 66113/121214_Working_with_troubled_families_FINAL_v2.pdf.

DEPARTMENT FOR COMMUNITIES AND LOCAL GOVERNMENT. (2014) [online]:

https://www.gov.uk/government/policies/ helping-troubled-families-turn-their-lives-around. 
EVANS, J, DAVIES, B. and RICH, E. (2013) 'We/You can tell talk from matter: A conversation with Håkan Larsson and Mikael Quennerstedt', Sport, Education and Society, Vol. 19, No. 5, p. 356-370

EVANS, J, DAVIES, B. and WRIGHT, J (Eds.). (2004)Body Knowledge and Control: Studies in the Sociology of Physical Education and Health. London: Routledge.

EVANS, J, RICH, E, DAVIES, B. and ALLWOOD, R. (2008).Education, Disordered Eating and Obesity Discourse. Oxon: Routledge.

EVANS, J, RICH, E, DE-PIAN, L. and DAVIES, B. (2011) 'Health imperatives, policy and the corporeal device: Schools, subjectivity and children's health', Policy Futures in Education, Vol. 9, No. 2, p. 328-340.

FARRELL, A. (2011). Fat Shame: Stigma and the Fat Body in American Culture.New York: New York University Press.

FOOD AND DRINK FEDERATION, (2004) Join the Activators: The Food and Drink Federation Campaign for Healthy Eating and Physical Activity. London: The Food and Drink Federation.

FOX, R. and SMITH, G. (2011). 'Sinner ladies and the gospel of good taste: Geographies of food, class and care'. Health \& Place, Vol. 17, p. 403-412.

FROHLICH, K. and ABEL, T. (2014) 'Environmental justice and health practices: Understanding how health inequities arise at the local level', Sociology of Health \& IIIness, Vol. 36, p. 199-212.

FUSCO, C. (2006) 'Inscribing healthification: Governance, risk, surveillance and the subjects and spaces of fitness and health, Health \& Place, Vol. 12, No. 1, p. 65-78.

GARD, M. (2011) 'Truth, belief and the cultural politics of obesity scholarship and public health policy',Critical Public Health, Vol. 21, No. 1, p. 37-48

GARD, M. and WRIGHT, J. (2005). The Obesity Epidemic: Science, Morality and Ideology. Oxon: Routledge.

GIROUX, H. (1992). Border Crossings. London: Routledge.

GIROUX, H. (2003) Public Spaces, Private Lives: Democracy Beyond 9/11. Oxford UK: Rowman \& Littlefield Publishers, INC.

GIROUX, H. (2004) 'Public pedagogy and the politics of neo-liberalism: Making the political more pedagogical', Policy Futures in Education, Vol. 2, No. 3/4, p. 494-503.

GRAHAM, H. (2012) 'Smoking, stigma and social class', Journal of Social Policy, Vol. 41, No. 1, p. 83-99

HALL, S. (2011) 'The neo-liberal revolution', Cultural studies, Vol. 25, No. 6, p.705-728.

HARK, L. and DEEN, D. (2005). Nutrition for Life: The Definitive Guide to Eating Well for Good Health.London: Dorling Kindersley.

INGHAM, A. (1997). Toward a department of physical cultural studies and an end to tribal warfare in FernandezBalboa J-M (Ed.) Critical Postmodernism in Human Movement, Physical Education and Sport Albany: State University of New York Press, p. 157-180.

JEFFERSON, A. (2006) 'Breaking down barriers - examining health promoting behaviour in the family. Kellogg's family health study 2005', British Nutrition Foundation Nutrition Bulletin, Vol. 31, p. 60-64.

JEFFORDS, S. (1994). Hard Bodies: Hollywood Masculinity in the Age of Reaganomics New Brunswick, NJ: Rutgers.

LAMONT, M. (2009) Racism, health and social inclusion in Hall P and Lamont M (Eds.)Successful Societies: How Institutions and Culture Affect Health. New York: Cambridge University Press, p. 151-168.

LATOUR, B. (2004) 'Why has critique run out of steam? From matters of fact to matters of concern'Critical Inquiry, Vol. 30, No 2. p 225-248.

LAWLER, S. (1999) "Getting out and getting away': Women's narratives of class mobility',Feminist Review, Vol. 63 (Autumn), p. 3-24.

LAWLER, S. (2004) 'Rules of engagement: habitus, power and resistance',Sociological Review, Vol. 52, No. 2, p. 110-128. 
LAWLER, S. (2005a) 'Introduction: Class, culture and identity',Sociology, Vol. 39, No. 5, p. 797-806.

LAWLER, S. (2005b) 'Disgusted subjects: The making of middle class identities',Sociological Review, Vol. 53, No. 3, p. 429-446.

MANSFIELD, L. and RICH, E. (2013) 'Public health pedagogy, border crossings and physical activity at every size', Critical Public Health, Vol. 23, No. 2 p: 356-370

MARMOT, M. and WILKINSON, R. (2001) 'Psychosocial and material pathways in the relation between income and health: A response to Lynch et al.', BMJ, Vol. 322, No. 7296, p. 1233-6.

MILLER, T. (2001) What it is and what it isn't: introducing . . . Cultural studies in Miller T (Ed.)A Companion to Cultural Studies. Oxford, UK: Blackwell Publishers Ltd, p. 1-20.

MOL, A. (2008) The Logic of Care: Health and the Problem of Patient Choice, London: Routledge.

MONAGHAN, L. (2005) 'Discussion piece: A critical take on the obesity debate',Social theory \& health, Vol. 3, No. 4, p.302-314.

MONAGHAN, L. (2008) Men and the War on Obesity: A Sociological Study. Oxon and New York: Routledge.

MONAGHAN, L. (2013) 'Extending the obesity debate, repudiating misrecognition: Politicising fatness and health (practice), Social Theory \& Health, Vol. 11, No. 1, p. 81-105.

MUNT, S. (2000). Introduction in Munt S (Ed.)Cultural Studies and the Working Class: Subject to Change London: Cassell, p. 1-18.

NHS. (2013) Reward people who live heathily, says 'think-tank'. NHS Choices [online]: http://www.nhs.uk/news/2013/03March/Pages/ Reward-people-who-live-healthily-says-think-tank.aspx.

ONG, B. N, ROGERS, A, KENNEDY, A, BOWER, P, SANDERS, T, MORDEN, A, CHERAGHI-SOHI, S, RICHARDSON, J. C. and STEVENSON, F. (2014) 'Behaviour change and social blinkers? The role of sociology in trials of self-management behaviour in chronic conditions', Sociology of Health \& IIIness, Vol. 36, p. 226-238.

PEACOCK, M, BISSELL, P. and OWEN, J. (2013) 'Shaming encounters: Reflections on contemporary understandings of social inequality and health', Sociology, Vol. 48, No. 2, p. 387-402.

PUHL, R. M. and HEURER, C. (2010) 'Obesity stigma: Important considerations for public health',American Journal of Public Health, Vol. 100, No. 6, p. 1019-1028.

RAIL, G. and LAFRANCE, M. (2009) 'Confessions of the flesh and biopedagogies: Discursive constructions of obesity on Nip/Tuck', Medical Humanities, Vol. 35, p. 76-79.

RICH, E. (2014) "Digitising Fat' - Digital technologies, Embodiment and the Governance of Fat, Paper presented at the 2nd Annual International Weight Stigma Conference, June 24th 2014, Canterbury, UK.

RICH, E, EVANS, J. and DE PIAN, L. (2011). Children's bodies, surveillance and the obesity crisis in Rich E Monaghan L and Aphramor L (Eds.) Debating Obesity: Critical perspectives. Basingstoke: Palgrave Macmillan, p.139-163.

RICH, E, MONAGHAN, L. and APHRAMOR, L. (Eds.) (2010)Debating Obesity: Critical Perspectives. Palgrave Macmillan.

ROTHBLUM, E. and SOlOVAY, S. (Eds.) The Fat Studies Reader. New York: New York University Press.

SCAMBLER, G. (2012) 'Health inequalities', Sociology of Health \& IIIness, Vol. 34, No. 1, p. 130-46.

SHILDRICK, T, MACDONALD, R, WEBSTER, C. and GARTHWAITE, K. (2010) The low-pay, no-pay cycle. Understanding recurrent poverty', Report for the Joseph Rowntree Foundation [online]: http://www.jrf.org.uk/sites/files/jrf/unemployment-pay-poverty-full.pdf.

SILK, M. and Andrews, D. (2011) 'Toward a physical cultural studies',Sociology of Sport Journal, Vol. 28, No. 1, p. 4-35.

SKEGGS, B. (2004) Class, Self, Culture. London: Routledge.

SKEGGS, B. (2005) 'The making of class through visualising moral subject formation',Sociology, Vol. 39, No. 5, 
p. $965-982$

SKEGGS, B. and WOOD, H. (2004) 'Notes on ethical scenarios of self on British reality tv' Feminist Media Studies, Vol. 4, No. 1, p. 205-208.

SLACK, J. (1996) The theory and method of articulation in cultural studies in Morley D and Chen K (Eds.)Stuart Hall: Critical Dialogues in Cultural Studies. London: Routledge, p. 112-127.

SOLOVAY, S. and ROTHBLUM, E. (2009) Introduction in Rothblum E and Solovay S (Eds.)The Fat Studies Reader. New York: New York University Press, p. 1-10.

TOWER HAMLETS.GOV (2012) 'Tackling 'Troubled' Families in Tower Hamlets. Learning the lessons from a successful inner-city borough', [online]: http://horizon2020projects.com/wpcontent/uploads/2014/01/2Gov8-Tower-Hamlets_10373-8pBooklet.pdf.

TIMMINS, N. (2012) "Never Again? the Story of the Health and Social Care Act 2012,' London: King's Fund and Institute for Government.

TURNER, G. (2003). British Cultural Studies: An Introduction(3rd edition). London: Routledge.

TYLER, I. and BENNETT, B. (2010) "Celebrity chav': Fame, femininity and social class',European Journal of Cultural Studies, Vol. 13, No. 3, p. 375-393.

VAN AMSTERDAM, N. (2013) 'Big fat inequalities, thin privilege: An intersectional perspective on 'body size' European Journal of Women's Studies, Vol. 20, No 2. p. 155-169.

VAN AMSTERDAM, N. (2014) 'Fastidious fatness: An intersectional approach to weight stigmatisation, Paper presented at the 2nd Annual International Weight Stigma Conference, June 24th 2014, Canterbury, UK.

VINCENT, C, BALL, S. and BRAUN, A. (2010a) "It's like saying 'coloured": Understanding and analysing the urban working classes', The Sociological Review, Vol. 56, No. 1, p. 61-77.

VINCENT, C, BALL, S. and Braun, A. (2010b) 'Between the estate and the state: Struggling to be a 'good' mother', British Journal of Sociology of Education Vol. 31, No. 2, p. 123-138.

WALKERDINE,V. (1990) School Girl Fictions. London, UK: Verso.

WALKERDINE, V. (2009) Biopedagogies and beyond in Wright $\mathrm{J}$ and Harwood V (Eds.)Biopolitics and the Obesity Epidemic: Governing Bodies. New York: Routledge, p.199-207.

WARIN, M. (2014) 'Material feminism, obesity science and the limits of discursive critique',Body and Society, Advanced online publication. DOI: 10.1177/1357034X14537320.

WARIN, M, TURNER, K, MOORE, V. and DAVIES, M. (2008) 'Bodies, mothers and identities: Rethinking obesity and the BMI', Sociology of health and illness, Vol. 30, No. 1, p.97-111.

WEINER, B, PERRY, R. and Magnusson J. (1988) 'An attributional analysis of reaction to stigmas',Journal of Personality and Social Psychology, Vol. 55, No. 5, p. 738-748

WEIS, L. (2004) Class Reunion. The Remaking of the American White Working Class. New York: Routledge.

WOLFF, J. (1997) 'Cultural studies and the sociology of culture', Invisible Culture [online]. https://www.rochester.edu/in_visible_culture/issue1/wolff/wolff.html.

WRIGHT, J. (2009) Biopower, biopedagogies and the obesity epidemic in Wright J and Harwood V (Eds.) Biopolitics and the 'Obesity Epidemic': Governing Bodies, New York: Routledge, p.1-14.

WRIGHT, J. (2014) Beyond Body Fascism: The Place for Health Education in Fitzpatrick K and Tinning R (Eds.) Health Education: Critical Perspectives. Oxon and New York: Routledge.

WRIGHT, J. and HARWOOD, V (Eds.) (2009)Biopolitics and the 'Obesity Epidemic': Governing Bodies. New York: Routledge.

ZIVKOVIC, T, WARIN, M, DAVIES, M. and Moore, V. (2010) 'In the name of the child: The gendered politics of childhood obesity', Journal of Sociology, Vol. 46, No. 4, p. 375-392. 